\title{
TRADITIONAL KNOWLEDGE: AS INTELLECTUAL PROPERTY, IT'S PROTECTION AND ROLE IN SUSTAINABLE FUTURE
}

\author{
Abirami A. B and Sujee $P$ \\ Law Student, Sastra Deemed to be University, India
}

\begin{abstract}
This paper primarily discusses the definition of traditional knowledge with emphasis on traditional medicine. The role of traditional medicine is vital as it is has been there for ages passed on from generation to generation. India is a country which possesses rare and useful natural resources in abundance. So a country like this is in need of safeguarding its traditional medicinal knowledge. The paper extensively deals with, to what extent intellectual property rights can protect the traditional knowledge. Developing countries are expected to protect their indigenous knowledge as it boosts their sustainable development in many aspects. Bio piracy is an issue, which is required to be looked into as the repercussions of this issue causes heartburn amongst those who possessed the knowledge and granting of wrong patents. It also has its own positive dimension, where it has led to do documentation and changes in patenting system. The paper also discusses whether the positive dimension can possibly protect traditional medicines. Various landmark cases where India challenged the wrong patents based on traditional knowledge has been extensively dealt with as examples which glorify India's measures to protect its own knowledge. And there arises a question whether sui generis is an effective positive protection system with respect to India has also been discussed elaborately. The challenges in pleasing every stakeholder is a complex process and so it can be done only to certain extent. So the balancing of the rights of the stake holders and at the same time protecting the indigenous medical knowledge is necessary. So the paper presents the possible measures that could be adopted to overcome the limitations of bringing traditional medicines under intellectual property rights.
\end{abstract}

Key words: Compulsory Licensing; Instances of Compulsory Licensing in India; Compulsory Licensing as governed by international legal jurisprudence.

Cite this Article: Abirami A. B and Sujee P, Traditional Knowledge: As Intellectual Property, It's Protection and Role in Sustainable Future. International Journal of Intellectual Property Rights, 10(2), 2019, pp.1-9. http://iaeme.com/Home/issue/IJIPR?Volume=10\&Issue $=2$

\section{INTRODUCTION}

Traditional knowledge (TK), indigenous knowledge (IK), traditional biological knowledge (TEK) and nearby knowledge all around imply knowledge systems embedded in the social traditions of regional, indigenous, or neighbourhood gatherings. Traditional Knowledge Systems go back to two million years, when man began making his instruments and interfacing with nature. Since the beginning of history, totally unique individuals have added to various parts of science and innovation, commonly in a way including intuitive contacts crosswise over societies isolated by enormous separations.[1] 
Creating nations have since a long time ago upheld for worldwide assurance of traditional knowledge while created nations have opposed development on the issues. The greater part of the worldwide exchange about the traditional knowledge has been occurred inside the idea of licensed innovation structure. The WIPO has been the essential facilitator of the discourse.

Assurances of the Traditional Knowledge of the neighbourhood and indigenous gatherings seem, by all accounts, to be a champion among the most contentious and obfuscated issue. The chronicled progression of the security of licensed innovation in the wake of individual private property rights, poked, the traditional knowledge and the inventive practice centred around it outside the space of the formal protected innovation insurance framework. The new thousand years presents real test to the worldwide genuine gathering to set new worldwide legitimate standard for handling the issue of licensed innovation security hurl open by the building headways. Traditional Knowledge was managed as Knowledge when all is said in done society belittles for nothing out of pocket abuse without showing any gratefulness or compassion towards the battle by the gatherings to shield and publicize the equivalent.

There are around 100 million woods occupants in India, most of whom fit in with innate gatherings. The woodlands outfit them with sustenance, giving both timber and non-timber woods produce. In this manner, the forested areas occupants have all through the multi year's collected data from the trademark condition around their gathering. This gathering has in a single sense been appreciatively shielded from the strategies for cutting edge man and has carried on the shows of their forebears. By and large, the forested areas and its inhabitants accommodate India ample data about the standard estimation of various timberland things.

\section{UNDERSTANDING TRADITIONAL KOWLEDGE}

Traditional knowledge will be knowledge, know-how, aptitudes and practices that are created, supported and passed on from age to age inside a network, frequently shaping piece of its social or otherworldly personality

\section{Meaning}

According to the official definition distributed by the World Intellectual Property Organization (WIPO), traditional knowledge is characterized as, "custom based scholarly, masterful, or logical works; exhibitions; developments; logical disclosures; structures; imprints, names, and images; undisclosed data; and all other convention based advancements and manifestations coming about because of scholarly action in the mechanical, logical, abstract or creative fields." [2]

Traditional knowledge alludes to the knowledge, developments and routine with regards to indigenous networks round the world. This is regularly the data that has been saved in human memories and not written in wherever, it's available through review on apply of scholarly aptitudes in an accommodating strategy in everyday life.

\section{Traditional Knowledge as Intellectual Property}

Traditional knowledge shows any work or workmanship which is a finish of instructs development or knowledge that has been disregarded the years through ages. Under the definitions given by WIPO, the significance of traditional knowledge does exclude anything which isn't a work of knowledge or scholarly activity in any field. This significance gives a wide extension for the term traditional knowledge.

Traditional knowledge is to a great extent portrayed by ethnic gatherings or spaces. For the most part traditional knowledge is imagined inside the possibility of "indigenous" or "traditional" gatherings of individuals. Traditional knowledge is any knowledge or aptitude that has been learnt by an indigenous or traditional gathering of individuals through ages. In spite of the fact that there are no particular simultaneousness as to indigenous individual in any all inclusive law, there are sure qualities identified with the gatherings. 
One of the principle issues of traditional knowledge is its security as protected innovation. One of the essential advantages and favorable position is the insurance of such indigenous gathering of individuals. Such assurance is likewise important to shield the way of life and legacy of the social gatherings.

\section{Existing Regime and Traditional Knowledge}

Does traditional knowledge fall inside the ambit of licensed innovation? Traditional knowledge isn't an innovation or bit of craftsmanship as in the protected innovation. Traditional knowledge does not by any stretch of the imagination fall inside the importance of licensed innovation. Traditional knowledge to a degree is secured under different licensed innovation laws yet there is no particular law to guarantee total assurance. A SUI GENERIS law is vital for this region to guarantee unending security in light of the fact that traditional knowledge does not fall inside the structure of licensed innovation. Such a law will ensure

old collective works and knowledge for their esteem however they don't altogether fall inside the importance of protected innovation. There are sure are which are like licensed innovation and there various regions where they contrast, in this way a few zones are secured while others are definitely not. For example, trademark laws can be utilized to ensure merchandise, results of explicit gatherings, prized formula laws can be utilized to save the traditional knowledge that has not yet been uncovered, topographical signs help to secure the products of a particular gathering geologically from others. For instance, Tirupati laddu separates itself topographically from other laddu's. Different logos of the organizations are secured through trademarks.

Creating countries are more worried for such assurance as opposed to created countries. Creating countries like India have a few common assets in plenitude which is of high esteem. Security of such assets winds up vital for financial improvement of the country. A Sui Generis law guarantees such assurance and financial advancement of the Nation.

\section{Patent and Traditional Knowledge}

The manner in which Patent rights have been made in cutting edge exchange, traditional knowledge can't be guaranteed security. For instance, traditional knowledge can't be licensed in light of the fact that such knowledge does not present innovative character, by virtue of the trademark nonattendance of oddity. Traditional knowledge is additionally generally hung all in all by gatherings, rather than by individual holders. This traditional knowledge is data that is transmitted from age to age generally inside the gathering or in the families inside the gathering in an oral structure with no agreeable or united documentation. This has brought about traditional knowledge being underestimated and limited. In reality, one of the misgivings in these gatherings is that if the knowledge were to be recorded it would have been lost to the gathering by seizure.

Comprehensively, licenses can be characterized as selective rights allowed for an innovation, either an item or a procedure that offers another specialized answer for a particular issue. A patent lingerie the honour of an imposing business model to a designer who has used his knowledge and capacities to convey an item or procedure which is new, incorporates an imaginative advance and is fit for modern application. The TRIPS Agreement similarly has a couple of arrangements having constrained application to the security and assurance of Traditional Knowledge. Revealing traditional knowledge which structures some portion of a development and of the cutting edge or earlier workmanship will push the progression of science by making an inspiration for keeping up traditional knowledge systems. This will occur by traditional knowledge being comprehensively and all around acknowledged inside "western" or "present day" creation assurance frameworks and transforming into a reference point inside the general tasks of the global patent framework.

\section{IMPORTACE OF TRADITIONAL KNOWLEDGE}

Traditional knowledge has been a constituent piece of the lives of offspring of the dirt and accordingly all the indigenous network. Use has been done of Traditional Knowledge by these gatherings in their ordinary 
lives anyway even more importantly as a gadget towards better and mindful organization of rare assets. This Knowledge has been acknowledged by these indigenous gatherings for a reasonable advancement and is imperative to their quality and their survival and the survival of their common surroundings for usage by their future age.

For creating countries, traditional knowledge is a key for ensuring nourishment security and soundness of people in the creating scene. According to the World Health Organization, in various countries traditional arrangement of drug gives the main efficient fix to destitute individuals. Various contemporary medications have been resolved from the knowledge of retouching properties of plants, creatures, etc. Traditional practices and considerations of neighbourhood agriculturists have provoked the headway of most recent cultivating techniques.

\section{REQUISITE TO PROTECT TRADITIONAL KNOWLEDGE Background}

Lately, indigenous gatherings, nearby gatherings, and governments - for the most part in creating countries have mentioned Intellectual Property security for traditional appearances of inventiveness and advancement, which, under the conventional Intellectual Property structure, are all things considered seen as being in open space, and thusly free for anybody to utilize. Indigenous society, nearby networks and various countries dismiss an "open area" status of Traditional Knowledge and battle that this opens them up to unfortunate misappropriation and misuse.

For Example; an indigenous society tune could be adjusted and somebody may copyright it and not give any affirmation to the network which made the melody and furthermore the advantages emerging from the abuse of the tune may not be imparted to the network; or innovations got from Genetic Resources[3]could be licensed by outsiders, bringing up issues with regards to the connection between the patent framework and the preservation and feasible utilization of biodiversity and the impartial sharing of advantages[4]. Seeing the traditional segments as protectable Intellectual Property would enable their holders to have a state over their usage by others.

\section{Need and Object of Protection}

Security of traditional knowledge has constantly involved significance in context of the nations like India. The Turmeric patent case and the Neem patent case are the Landmark Cases whereby one can perceive how therapeutic plants and Traditional Knowledge are misused by Commercialist. The knowledge of this sort has unendingly been in the hands of the indigenous and nearby gatherings which are, no uncertainty manhandled and misused without an offer of advantage being given to them. These advantages are used inside such a style, to the point that prompts bio robbery for example bio robbery. The uncommon and one of a kind sort of such knowledge makes it inadmissible for assurance by the current legitimate structure. Traditional knowledge not just gives as a methods for occupation to the nearby and indigenous gatherings yet in addition works as an instrument which empowers better administration of their eco-framework.

Traditional knowledge is used as a contribution to introduce day business endeavors, for instance, pharma, natural prescriptions, present day wear, excellence care items, common pesticides, horticulture and so on. In like manner guaranteeing security of traditional knowledge can possibly upgrade the financial execution of various creating countries by empowering increasingly imperative business

\section{INDIA'S EFFORT IN PROTECTION OF TRADITIONAL KNOWLEDGE}

Some Specialist are of the feeling that Traditional Knowledge ought to be verified and ensured under the patent routine however then the criteria of Novelty and Inventive advance won't be satisfied if there should arise an occurrence of Traditional Knowledge. Since there is nonattendance of Trade Secret related law in India the Trade Secret strategy will likewise neglect to secure Traditional Knowledge. These conditions clear the mist that present Intellectual property framework isn't very much prepared to secure Traditional 
Knowledge. Regardless, certain means are taken by India in advancement of ensuring customary learning in the wake of understanding its significance and considering different dangers of bio robbery, through after activities.

\section{ENACTMENT OF VARIOUS LEGISLATIONS:}

\section{The Patents (Amendment) Act, 2005}

This law makes it compulsory for the patent candidates to uncover in the patent applications the wellspring of beginning of the organic material and related information utilized in the innovation[5]. It additionally envelops arrangement for the assurance of biodiversity and customary information by declining to allow patent or disavow it if the application improperly makes reference to the wellspring of geological cause of organic material[6], or the innovation guaranteed was identified with conventional learning oral or something else, of any neighbourhood or indigenous network in India or something else. This measure is taken to guarantee the assurance of fables or information having a place with nearby or indigenous network of any nation. Consequently there is an exertion made by the Legislature yet little yet essential in perspective on enveloping the security of the customary information. Since there exists a few parts of Traditional information that could be incorporated into the universe of Patent law however not totally but rather to some degree, it is important to guarantee that any endeavors that could be made are contributed and there is severe usage of the equivalent.[7]

\section{The Protection of Plant Variety and Farmers' Rights Act (PPVFR Act), 2001}

The PPVFR Act however not legitimately identified with security of Traditional Knowledge, has essential arrangements of advantage sharing and ranchers' rights. The plant assortments not patentable under the Patents Act are explicitly managed under the PPVFR Act. This law secures the enthusiasm of the ranchers for their commitment in rationing improving and making accessible plant hereditary assets so as to grow new plant assortments. The primary focal point of this Act is on characterizing plant reproducer's rights (PBRs). The demonstration contains arrangements in advancement of evenhanded sharing of advantages radiating from the utilization of plant hereditary assets that may accumulate to a raiser from the deal and transfer of seeds or planting, material of a secured assortment.

\section{The Biological Diversity Act, 2002}

This demonstration offers impact to the command of CBD and to some degree, to the Plant Genetic Resources for Food and Agriculture (PGRFA) Treaty. This enactment is increasingly unequivocal in its methodology towards Traditional Knowledge. Any individual planning to apply for any Intellectual Property in India or outside the nation, needs to accommodate advantage sharing as dictated by the National Biodiversity Authority which manages access to use of organic assets.

\section{Traditional Knowledge Digital Library (TKDL)}

Documentation of effectively existing information, available in open area, on various conventional systems of medication has turned out to be essential to ensure the matchless quality and the power of this customary learning and to verify it from being mishandled in the type of licenses on non-unique advancements, and which has been an issue of national concern. In 1999, an interdisciplinary team was comprised for making a methodology paper on setting up a Traditional information Digital Library (TKDL). The venture TKDL was started in the year 2001 by the Government of India, to ward of occurrences of theft. India's TKDL is a communitarian venture between the Council of Scientific and Industrial Research (CSIR), and the Department of AYUSH, it is a home-developed exertion to guarantee patent workplaces around the globe don't concede licenses for applications established on India's abundance of age-old Traditional Knowledge. It encourages information and data on Traditional learning existing in the nation, in dialects what's more, position comprehensible to patent inspectors at International Patent Offices. By and by, the TKDL contains information on 65,000 plans in ayurveda, 70,000 in Unani 
and 3,000 in Siddha, from 14 old books[8]. Access to TKDL is managed through an 'Entrance Agreement', on state of privacy.

\section{INTERMINABLE PROTECTION AND ITS IMPLICATIONS}

In the year 2009, an African Group presented a paper which joined the distinctive stands taken by the WIPO IGC members and made proposals for pushing ahead[9]. The 2009 African Group proposition noticed that a couple of individuals search for never-ending insurance though others prescribe that there is a need to adjust the privileges of the pioneers and individuals when all is said in done. The African Group recommends, as a feature of things to come street, that customary learning ought to acquire ceaseless assurance. This proposition is predictable with the perspectives on numerous other creating countries. So as to affirm the sufficient assurance of customary information, it's controlled that the privilege should be inconclusive and even retroactive to shield recorded works. Inferable from the between generational nature of the conventional learning, unending insurance is viewed as an essential part in making a proficient lawful routine. In addition, since certain networks may item to the usage of works related with their social character, uncertain assurance is foremost for certain conventional learning holders. Obviously, some of the announced destinations of conventional information security are particular from the boosting job of protected innovation. This could be another reason why customary learning doesn't work among an exemplary scholarly property demonstrate. Be that as it may, on the grounds that Traditional Knowledge, similar to licensed innovation, is in regards to the legitimate treatment of scholarly manifestations and skill, a few pieces of the lawful structure of protected innovation law remain applicable. Extraordinarily, the term restriction is appropriate to the worry with respect to the effect of rights in immaterial product or merchandise on human improvement factors that depend on ceaseless access to learning and information based wares. Be that as it may, because of its intergenerational nature, customary learning might be ensured uncertainly and even retroactively. This probably won't be in venture with the value situated goal of access to moderate conventional learning wares. Accordingly, any inconclusive right recognized should be similarly less prohibitive in order to not affront the standard of a harmony between the interests of the correct holder and furthermore the general population. As a kind of universally perceived licensed innovation with no term of insurance, topographical signs have all the earmarks of being outstandingly significant to the customary learning talk. Be that as it may, an indispensable refinement between customary information and geological signs is that a topographical sign, similar to a trademark, gives security to the notoriety of a particular thing yet no fundamental learning. An unending term of insurance for conventional learning would apparently stretch out not exclusively to the usage of names, for instance, yet additionally to the applicable substantive information. Subsequently, the effect of an interminable customary learning right would not be similar to the inconclusive insurance delighted in by topographical signs. The conventional learning right would ostensibly be more grounded. At present, there is no impalpable property right that offers uncertain insurance over utilizations identifying with substantive learning.[10]

\section{CUSTOMARY KNOWLEDGE AS A MEANS OF SUSTAINABLE DEVELOMENT FOR SUSTAINABLE FUTURE}

\section{Benefit Sharing}

Arrangements for the impartial dissemination of any advantages emerging out of creations and developments and practices related with the utilization and uses of learning are additionally fused in the legitimate system. The advantage sharing incorporates the accompanying:[11]

1. Allow of joint responsibility for Property Rights to the advantage claimers which incorporate all the conservers of the natural assets, makers and holders of learning and data and people or networks rehearsing such advantages.

2. Exchange of innovation for satisfactory thought from the advantage sharers to bodies needing to utilize the innovation. 
3. Situating of creation, innovative work offices which will give work to and generally encourage the improvement of expectations for everyday comforts of the advantage claimers.

4. Asking upon the bodies who are applying for a patent to relate Indian researchers, advantage claimers and the neighborhood individuals with the innovative work in the natural assets, bio-overviews and biousage lastly;

5. Direct installment of money related remuneration and other non-fiscal advantages to the advantage claimers.

\section{A Narrow Right-Limited Control}

The traditional knowledge right, which is affected to render the potential insurance all the more appealingly restricted to command over the business utilization of it. In this unique situation, the 'business use' is should have been characterized with the goal that it would be clear what is incorporated into the disallowed demonstrations. For instance, 'a correct holder ought to likely not have the capacity to forestall the private resale of a traditional knowledge great or the private utilization of traditional skill'. For instance, a contention could be made that counteracting licenses identified with the therapeutic employments of turmeric guarantees that the ability remains freely accessible. On account of turmeric, two Indian nationals looked for an American patent dependent on Indian skill. A traditional knowledge right could have been used to guarantee that the expertise stays accessible to the Indian and worldwide network instead of getting to be liable to a patent held by two people.

Furthermore, the engineered compound which is made dependent on the traditional knowledge in regards to the employments of a normally happening substance, with the arrangement of logical advancement could be thwarted by the failure to create and market it. Further, it is engaged that the powerlessness to market the ability traditional knowledge antagonistically influences the use of the traditional based knowledge to people in general. In the event that the expertise isn't broadly known by the general population everywhere, the utility of that knowledge is said to be constrained to the knowledge holder of little gathering of the applicable network. In such an occasion, it might just be through commercialization that the open would profit by the expertise and accordingly get to traditional knowledge related merchandise. Thusly, for this situation, power over the commercialization of such knowledge would be conflicting with human improvement objectives, for example, openness and reasonableness as for traditional knowledge items. Along these lines, it is given that there are no otherworldly or religious perspectives to the traditional knowledge, a correct that accommodates command over the business employments of the traditional knowledge ought to be time constrained.

\section{REQUIREMENT FOR A SUI GENERIC SYSTEM}

The insurance of traditional knowledge contains number of arrangement issues, remarkably the destinations and modalities of such security, and its effect and suggestions for its alleged and planned recipients. Such issues are confounded since there are expansive contrasts in regards to the meaning of the topic, the explanation behind security, and the instrument for accomplishing its point. The issues concerning traditional knowledge should be tended to in a totally extraordinary way, including moral, moral, and natural and financial issues just as at the worldwide dimension conjointly, every one of the nations need to shield their antiquated and traditional knowledge and indigenous knowledge by a proper and reasonable sui generis enactments. By and large, ordinary IP frameworks and adjustments thereof are not viewed as adequate to take into account the exceptional character of Traditional Knowledge. For instance, when network individuals develop inside the Traditional Knowledge structure, they may utilize the patent framework to secure their advancements. In any case, Traditional Knowledge "all things considered"- knowledge that has old roots and is regularly casual and oral, isn't ensured by ordinary IP frameworks. This has incited various nations and districts to build up their very own particular sui generis (explicit, unique) frameworks for securing Traditional Knowledge. Sui generis measures are particular measures pointed only at tending to the qualities of explicit topic, for example, Traditional Knowledge. 
What makes an Intellectual Property framework a sui generis one is the trim of its highlights to legitimately oblige uncommon attributes and explicit approach needs. Along these lines India additionally needs to order a fitting enactment for the insurance of traditional knowledge.

\section{CONCLUSIONS AND SUGGESTIONS}

It is in this manner reasoned that Indigenous knowledge is the nearby knowledge that is remarkable to a culture or society. Different names for it include: 'neighborhood knowledge', 'society knowledge', 'individuals' knowledge', 'traditional astuteness' or 'traditional science'. This knowledge is passed from age to age, as a rule by overhearing people's conversations and social ceremonies, and has been the reason for farming, sustenance planning, medicinal services, training, protection and the wide scope of different exercises that continue social orders in numerous pieces of the world. Mulling over human advancement factors, for example, access to moderate traditional knowledge items; it gives the idea that worldwide interminable insurance of traditional knowledge would not be advantageous for creating nations or indigenous people groups.

In the universal setting, a period restricted right would be desirable over unending insurance of this between generational knowledge. The knowledge which is eternal in nature, and subsisted from the days of yore or, might be in the ongoing time is important to be ensured; as it is the conspicuous wonder that anything accessible anyplace is some place made by an individual or more than one individual, however the knowledge still initially has a place with them, so earlier insurance of right should be ensured to them as to their protected innovation so nobody else could encroach their privilege and name the property as his property. This routine with regards to naming another's property as one's very own property is being seen broadly in the present situation. In the light of the end, these proposals are being made as Future bearings, which are as:

1. Future headings are on a very basic level ward upon changes in political will by country states and the commercial sector. The improvement of structures that upgrade and encapsulates indigenous people groups' points of view and cooperation is long late. Indigenous knowledge can never again be viewed as a crude asset from which others advantage. Indigenous people groups' commitment to basic issues like ecological supportability, environmental change and asset the executives imply that it is to everybody's greatest advantage to grow better impartial and moral structures and organizations.

2. Indigenous individuals are asking that their social frameworks and methods for administering knowledge access and use be perceived as genuine. That they be regarded as caretakers/proprietors/nurturers of knowledge that is significant to many. That the overwhelming licensed innovation system, which has prohibited their interests, be reconfigured with the goal that it can ensure their interests as well. Indigenous gatherings are demanding that they likewise have ideal to get profits by knowledge that gets from their specific circumstances and depends on their authentic knowledge. These solicitations are standard, sensible and real and require prompt activity.

3.Rethinking how we do look into, how we conceptualize knowledge, how we share knowledge, how we perceive genuine covers in knowledge use and course, and the degree of the job of law in impacting our social requests of knowledge trade are beginning stages.

4. An improved Indian Patent Act offering space to the routine on Traditional Knowledge can encourage successful security to the knowledge just as the gatherings from where the knowledge has created. Additionally under the current Act, Prior workmanship includes divulgence of prior craftsmanship as well as whatever was before known by general society or was utilized anyplace on the planet, so if the criteria for patentability are appropriately connected the allowing of mistaken licenses would be maintained a strategic distance from, along these lines there would be no misuse of knowledge with no prizes to the holders.

Consequently, there is have to define the principles overseeing the Traditional Knowledge security and furthermore legitimate component to rebuff the violators and to protect the traditional knowledge accessible with the applicable networks. 


\section{KEYWORDS}

1. The Traditional Knowledge System', available at http://www.infinityfoundation.com/mandala/tks_overview_frameset.htm.

2. Intergovernmental committee on intellectual property and genetic resources, traditional knowledge and folklore Third Session Geneva, June 13 to 21, 2002.

3. Article 2 of the Convention on Biological Diversity (1992) defines "genetic resources" as "genetic material of actual or potential value."

4. http://www.wipo.int/edocs/pubdocs/en/tk/933/wipo_pub_933.pdf page 6

utilization of their organic and biological wealth and expanding export of commodities, merchandise, produces etc identified with traditional knowledge. A huge part of the planets crop diversity is in the care and keeping of agriculturists, farmers who pursue age old cultivating and land use practices in ecologically complex agricultural systems which facilitate the protection and preservation of bio diversity.

5. Patents ( amendment) act (India) 2005 ( No.15 of 2005), Under s. 10.4(d) D

6. Under the new provision, s. 64(p), a patent can be revoked when 'the complete specification does not disclose or wrongly mention the source or geographical origin of biological material used for the invetion'.

7. Traditional Knowledge, Traditional Cultural Expressions, and Intellectual property law in the asia-pacific region,edited by Christoph Antons, page no.330.

8. Traditional knowledge, traditional cultural expressions, and intellectual property law in the asia-pacific region, edited by christoph antons, page no.336.

9. Graham dutfield \& uma suthersanen, global intellectual property law 47-48 (2008);

10. The patent right, for example, allows the right holder to prevent others from using the invention and effectively, therefore, from utilizing the knowledge underlying the patent. However, the patent term is limited to 20 years from the date of filing. See TRIPS AGREEMENT

11. The Realities of Traditional Knowledge And Patents in India Dr. Mohan Dewan

\section{REFERENCES}

[1] Traditional Knowledge, Traditional Cultural Expressions and Intellectual Property Law In The AsiaPacific Region, By: Christoph Antons March 2009.

[2] Intellectual Property, Biogenetic Resources, and Traditional Knowledge by Graham Dutfield.

[3] Intellectual Property and Genetic Resources, Traditional Knowledge and Traditional Cultural Expressions available at

[4] http://www.wipo.int/edocs/pubdocs/en/tk/933/wipo_pub_933.pdf

[5] http://www.infinityfoundation.com/mandala/tks_overview_frameset.htm.

[6] J. Janewa Oseitutu, "Traditional Knowledge: is Perpetual protection of good idea" available at ipmall.info/fosted_resources/IDEA/idea-vol50- no4-oseitutu.pdf. 